\title{
Effect of cimetidine on cyclophosphamide- induced liver toxicity in albino rats
}

\author{
Elias Adikwu', Bonsome Bokolo² \\ Lecturer ${ }^{1}$ Department of Pharmacology and Toxicology, Faculty of Pharmacy, Niger Delta University, Nigeria, Lecturer \\ ${ }^{2}$ Department of Pharmacology, Faculty of Basic Medical Sciences, Niger Delta University, Nigeria
}

Background: The clinical use of cyclophosphamide (CP) has been characterised by liver toxicity. Aims and Objectives: This research assessed the effect of cimetidine against CPinduced liver toxicity in a rat model. Material and Methods: Forty eight albino rats divided into 8 groups $(\mathrm{A}-\mathrm{H})$ of 6 rats per group were used for this study. Group A (control) was administered with water while groups B-D were administered with 5,10 , and $20 \mathrm{mg} / \mathrm{kg} /$ day of cimetidine intraperitoneally (ip) for 5 days respectively. Group E was administered with $150 \mathrm{mg} / \mathrm{kg}$ of $\mathrm{CP}$ ip on the $5^{\text {th }}$ day whereas groups $\mathrm{F}-\mathrm{H}$ were administered with 510 , and $20 \mathrm{mg} / \mathrm{kg} / \mathrm{day}$ of cimetidine for 5 days and CP ip on the $5^{\text {th }}$ day. Rats were subjected to an overnight fast and sacrificed on the sixth day. Serum was extracted from blood and liver function parameters were evaluated. Liver was excised and evaluated for biochemical parameters and histology. Results: $C P$ treatment had no significant $(P>0.05)$ effects on body and liver weights, but significant $(P<0.05)$ increases in alanine aminotransferase, alkaline phosphatase, aspartate aminotransferase, lactate dehydrogenase, gamma, glatamyl transferase, total bilirubin, conjugated bilirubin and malondialdehyde levels were observed when compared to control. Furthermore, significant $(\mathrm{P}<0.05)$ decreases in liver superoxide dismutase, catalase, glutathione and glutathione peroxidase were obtained in CP-administered rats when compared to control. The Liver of CP-treated rat shows hepatocyte necrosis around the central veins. However, $C P$-induced liver damage was significantly $(P<0.05$; $0.01)$ ameliorated in a dose-dependent manner in rats administered with cimetidine prior to the administration of CP. Conclusion: Cimetidine ameliorates cyclophosphamide-induced liver toxicity in albino rats.

Key words: Cyclophosphamide; Cimetidine; Liver; Toxicity; Rats

\section{INTRODUCTION}

Cancer is a disease that is associated with the abnormal proliferation and growth of living cells. ${ }^{1}$ A variety of approaches and methods are employed clinically for the treatment of cancer, however each of these approaches or methods have some significant limitations especially adverse effects. ${ }^{2}$ The methods used for the treatment of cancer include chemotherapy, surgery, hormone therapy and radiation. Chemotherapy, is one of the commonest and most frequent approaches used for the treatment of cancer, it delivers anticancer drugs systemically to patients for quenching the uncontrolled proliferation of cancerous cells. ${ }^{3}$ However, the success of chemotherapy has been limited by lack of selectivity and differentiation between tumor cells and normal cells resulting in insufficient drug concentrations in tumors, appearance of drug-resistant tumor cells and systemic toxicity. ${ }^{4}$ Cyclophosphamide (CP) is one of the commonly and widely used drugs for cancer chemotherapy. It is a cytotoxic alkylating agent with antitumor and immunosuppressant properties use for the treatment of chronic and acute leukemia, multiple myeloma, lymphomas, and solid tumours. ${ }^{5} \mathrm{CP}$ undergoes bio-activation by hepatic microsomal cytochrome P450 mixed function oxidase system to its active metabolites; phosphoramide mustard and acrolein. ${ }^{6}$ The antineoplastic effect of CP has been associated with phosphoramide mustard, whereas acrolein is linked to its toxic effects like 
cell death, apoptosis, oncosis and necrosis. ${ }^{7}$ In spite of its therapeutic importance, a wide range of adverse effects including hepatotoxicity have been reported with the use of CP. CP-induced hepatotoxicity has been characterised by altered liver function markers and the distortion of liver architecture. ${ }^{8}$ The precise mechanism by which CP causes hepatic injury is poorly known. However, studies suggest the action of acrolein through the generation of oxidative radicals like superoxide anion, hydroxyl radical, and hydrogen peroxide ${ }^{9}$ which are mutagenic to mammalian cells $^{10}$ and can attack DNA, proteins, and lipids causing pathogenesis. ${ }^{11}$

Cimetidine is a $\mathrm{H} 2$ blocker that inhibits gastric acid secretion and is largely used in the treatment of peptic ulcers. ${ }^{12}$ It works by binding to an $\mathrm{H} 2$-receptor located on the basolateral membrane of the gastric parietal cell, blocking histamine effects. ${ }^{13}$ It has been demonstrated to cause dose-related inhibition of cytochrome P-450-mediated oxidation both in vivo and in vitro. ${ }^{14,15}$ In addition to its use in the treatment of gastrointestinal ulcer, it could be reposition as a hepatoprotective agent. It has shown tremendous hepatoprotective effect in animal model of xenobioticinduced hepatotoxicity, ${ }^{16}$ probably by decreasing the covalent binding of xenobiotics to liver protein, gastrointestinal absorption and decreasing the rate of hepatic glutathione depletion. ${ }^{17}$ Also, cimetidine has a strong oxidative radical-scavenging activity which reduces the generation of oxidative radicals' thereby preventing oxidative damage. In addition, cimetidine is able to reduce iron-induced lipid peroxidation. ${ }^{18}$ The antioxidant effect of cimetidine has been attributed to its methylated imidazole with a sulfur and amino group containing side chain which is a powerful hydroxyl radical scavenger. ${ }^{19}$ Due to the absence of literature the present study examine the effect of cimetidine against cyclophosphamide-induced liver damage in albino rat.

\section{MATERIAL AND METHODS}

\section{Drugs and chemicals}

Cimetidine used was manufactured by Shandong Shenglu Pharmaceutical Co Ltd while cyclophosphamide was manufactured by Biochem Pharmaceutical Industries Ltd India. All other chemical substances used for this study are of analytical grade.

\section{Grouping of animals, drug administration and animal} sacrifice

Forty eight (48) rats of average weight $215 \mathrm{~g}$ which were randomised into eight groups of $n=6$ housed in a wire mesh cage were used for this study. The rats were allowed to acclimatize for 2 weeks in a well-ventilated room, under natural lighting condition. The directive of the 2010 European Parliament and the Council on the Protection of Animals used for scientific purposes was followed in the handling of the rats. Group A (Control) was administered with water. Groups B-D were administered with 5,10 , and $20 \mathrm{mg} / \mathrm{kg} /$ day of cimetidine ip for 5 days respectively. Group E was administered with $150 \mathrm{mg} / \mathrm{kg}$ of CP ip on the $5^{\text {th }}$ day. Groups F-H were administered with 510 , and $20 \mathrm{mg} / \mathrm{kg} /$ day of cimetidine ip for 5 days and CP ip on the $5^{\text {th }}$ day respectively. The rats were subjected to an overnight fast and were sacrificed under anaesthesia on the sixth day. Blood sample was collected from the heart and serum was extracted and evaluated for biochemical parameters. Liver was harvested, weighed and rinse in ice cold potassium chloride. The liver was buffered, homogenised and centrifuged. The supernatant was collected and evaluated for biochemical parameters.

Biochemical analysis and histological evaluation of the liver

Gamma glutamyl transferase, lactate dehydrogenase, aspartate and alanine aminotransferase, alkaline phosphatase, total bilirubin and conjugated bilirubin were measured using standard laboratory test kits (Randox Laboratories Ltd., Crumlin, UK). Liver protein content was evaluated according to the method of Gonall et al., $1949 .{ }^{20}$ while malondialdehyde was determined according to Buege and Aust $1978 .^{21}$ The method of Aebi $1984^{22}$ was used to assess catalase activity whereas superoxide dismutase was evaluated according to Sun and Zigman, $1978 .^{23}$ Reduced glutathione was measured as reported by Sedlak and Lindsay, $1968{ }^{24}$ whereas gluthathione peroxidise evaluation was performed according to Rotruck et al., 1973. ${ }^{25}$ Liver samples were harvested and fixed in formalin for $24 \mathrm{~h}$ and were processed and embedded in paraffin blocks. Slides were prepared (3-5 $\mu \mathrm{m}$ thick), stained with hematoxylin and eosin, and analyzed for pathology using light microscopy.

\section{RESULTS}

The administration of cimetidine did not produce significant $(\mathrm{P}>0.05)$ effects on body, and liver, weights and serum levels of AST, ALT, ALP, GGT LDH, TB and CB when compared to control. Also, effects were not significant (P>0.05) on liver levels of SOD, CAT, GSH, GPX, AST, ALT, ALP, GGT and LDH when compared to control (Table 1-3). The administration of CP did not produce significant $(\mathrm{P}>0.05)$ effects on the body and liver weights in comparison to control (Table 1). On the other hand, serum levels of AST, ALT, ALP, GGT LDH, TB and CB were significantly $(\mathrm{P}<0.05)$ increased in $\mathrm{CP}$-administered 
rats when compared to control. However, the serum levels of these parameters were significantly $(\mathrm{P}<0.05)$ restored in a dose-dependent manner in rats administered with cimetidine $+\mathrm{CP}$. The restored levels of these parameters differ significant at $\mathrm{P}<0.01$ in rats administered with $20 \mathrm{mg} /$ $\mathrm{kg}$ of cimetidine $+\mathrm{CP}$ in comparison to $\mathrm{CP}$-treated rats (Table 3). Furthermore, significant $(\mathrm{P}<0.05)$ increases in the liver levels of AST, ALT, ALP, GGT and LDH were obtained in $\mathrm{CP}$-administered rats when compared to control. It is worthy of note that the levels of these parameters were significantly $(\mathrm{P}<0.05)$ restored in a dosedependent manner in rats administered with cimetidine + CP. Significant difference was observed at $\mathrm{P}<0.01 \mathrm{in} 20 \mathrm{mg} /$ $\mathrm{kg}$ of cimetidine $+\mathrm{CP}$ administered rats when compared to CP-administered rats (Table 4). Furthermore, the liver levels of SOD, CAT, GSH and GPX were significantly $(\mathrm{P}<0.05)$ decreased in CP-treated rats when compared to control. Interestingly, SOD, CAT, GSH and GPX levels were significantly $(\mathrm{P}<0.05)$ increased in a dose-dependent manner in cimetidine $+\mathrm{CP}$ administered rats with most pronounced effects which were significant at $\mathrm{P}<0.01$ observed in rats administered with $20 \mathrm{mg} / \mathrm{kg}$ of cimetidine $+\mathrm{CP}$ (Table 4). The liver of the control rat and cimetidine administered rats showed normal histology (Fig $1 \mathrm{a}-\mathrm{d}$ ) while the liver of $\mathrm{CP}$-administered rat shows hepatocytes necrosis around the central veins (Fig 1 e). On the other hand, the liver of rat administered with $5 \mathrm{mg} / \mathrm{kg}$ of cimetidine $+\mathrm{CP}$, $10 \mathrm{mg} / \mathrm{kg}$ of cimetidine $+\mathrm{CP}$ and $20 \mathrm{mg} / \mathrm{kg}$ of cimetidine

\begin{tabular}{|c|c|c|c|c|}
\hline Dose (mg/kg) & Initial body weight (g) & Final body weight (g) & Absolute Liver weight (g) & Relative Liver weight (\%) \\
\hline Control & $217.2 \pm 10.6$ & $230.4 \pm 12.6$ & $8.94 \pm 0.19$ & $3.88 \pm 0.19$ \\
\hline CD 5 & $219.0 \pm 12.5$ & $221.8 \pm 10.0$ & $8.73 \pm 0.31$ & $3.93 \pm 0.19$ \\
\hline CD 10 & $213.8 \pm 10.0$ & $220.8 \pm 11.0$ & $8.79 \pm 0.12$ & $3.98 \pm 0.14$ \\
\hline CD 20 & $219.2 \pm 14.2$ & $217.2 \pm 13.7$ & $9.03 \pm 0.29$ & $4.15 \pm 0.18$ \\
\hline CYP 150 & $209.4 \pm 12.0$ & $210.6 \pm 12.2$ & $8.49 \pm 0.26$ & $4.03 \pm 0.13$ \\
\hline CD 5+CP & $213.0 \pm 14.4$ & $210.4 \pm 10.7$ & $8.79 \pm 0.20$ & $4.17 \pm 0.18$ \\
\hline CD $10+C P$ & $210.6 \pm 15.2$ & $220.0 \pm 14.1$ & $9.00 \pm 0.13$ & $4.09 \pm 0.11$ \\
\hline CD $20+C P$ & $218.8 \pm 12.2$ & $215.4 \pm 12.9$ & $9.01 \pm 0.09$ & $4.18 \pm 0.07$ \\
\hline
\end{tabular}

$\mathrm{CD}=$ Cimetidine, $\mathrm{CP}=$ Cyclophosphamide, values are expressed as Mean $\pm \mathrm{SEM}, \mathrm{n}=6$

Table 2: Effects of cimetidine on serum liver function markers of cyclophosphamide-administered albino rats

\begin{tabular}{|c|c|c|c|c|c|c|c|}
\hline Dose (mg/kg) & AST (U/L) & ALT (U/L) & ALP (U/L) & GGT (U/L) & CB ( g/dL) & TB (g/dL) & LDH (U/L) \\
\hline Control & $59.0 \pm 4.89$ & $66.0 \pm 3.14$ & $58.1 \pm 5.78$ & $0.78 \pm 0.01$ & $3.99 \pm 0.63$ & $7.95 \pm 0.40$ & $65.5 \pm 3.90$ \\
\hline CD 5 & $58.0 \pm 3.89$ & $64.2 \pm 4.25$ & $58.5 \pm 4.22$ & $0.76 \pm 0.03$ & $3.91 \pm 0.61$ & $7.85 \pm 0.46$ & $66.8 \pm 3.89$ \\
\hline CD 10 & $57.4 \pm 4.99$ & $62.9 \pm 4.82$ & $55.8 \pm 5.87$ & $0.83 \pm 0.02$ & $3.93 \pm 0.54$ & $7.87 \pm 0.34$ & $65.4 \pm 4.03$ \\
\hline CD 20 & $56.1 \pm 3.25$ & $61.2 \pm 4.26$ & $56.6 \pm 3.42$ & $0.81 \pm 0.07$ & $3.91 \pm 0.52$ & 7.890 .32 & $65.5 \pm 4.57$ \\
\hline CP 150 & $345.0 \pm 13.3^{a}$ & $245.8 \pm 12.4^{a}$ & $228.9 \pm 10.8^{a}$ & $6.04 \pm 0.48^{a}$ & $15.4 \pm 1.20^{a}$ & $40.3 \pm 4.89^{a}$ & $290.2 \pm 12.2^{a}$ \\
\hline CD5+CP & $248.3 \pm 11.5^{b}$ & $159.3 \pm 10.4^{b}$ & $158.8 \pm 8.64^{b}$ & $4.71 \pm 9.49^{b}$ & $10.4 \pm 0.75^{b}$ & $30.9 \pm 2.21^{b}$ & $183.7 \pm 13.7^{b}$ \\
\hline CD10+CP & $160.7 \pm 8.65^{b}$ & $96.4 \pm 5.71^{b}$ & $98.7 \pm 5.51^{b}$ & $2.49 \pm 0.19^{b}$ & $7.57 \pm 1.01^{b}$ & $21.6 \pm 1.54^{b}$ & $110.1 \pm 5.61^{b}$ \\
\hline
\end{tabular}

$\mathrm{CTD}=$ Cimetidine, $\mathrm{CP}=$ Cyclophosphamide, values are expressed as Mean $\pm \mathrm{SEM}, \mathrm{n}=6$

${ }^{a}$ Significant $(P<0.05)$ difference when compared to control

bSignificant $(P<0.5)$ difference when compared to $C P$

'Significant $(P<0.01)$ difference when compared to $C P$

\begin{tabular}{|c|c|c|c|c|c|}
\hline Dose (mg/kg) & AST (U/L) & ALT (U/L) & ALP (U/L) & GGT (U/L) & LDH (U/L) \\
\hline Control & $99.9 \pm 8.56$ & $122.3 \pm 9.93$ & $110.1 \pm 9.11$ & $2.23 \pm 0.34$ & $110.3 \pm 8.81$ \\
\hline CD 5 & $97.5 \pm 6.14$ & $119.8 \pm 8.75$ & $108.7 \pm 8.03$ & $2.41 \pm 0.76$ & $104.9 \pm 8.27$ \\
\hline CD 10 & $94.5 \pm 8.54$ & $119.2 \pm 9.91$ & $104.3 \pm 9.56$ & $2.29 \pm 0.52$ & $104.7 \pm 9.94$ \\
\hline CD 20 & $94.4 \pm 7.33$ & $123.8 \pm 10.4$ & $102.4 \pm 7.69$ & $2.24 \pm 0.46$ & $104.6 \pm 9.64$ \\
\hline CD 5+CP & $320.5 \pm 11.1^{b}$ & $350.9 \pm 14.3^{b}$ & $310.3 \pm 11.7^{b}$ & $6.58 \pm 0.37^{b}$ & $290.4 \pm 10.0^{b}$ \\
\hline CD 10+CP & $215.7 \pm 8.69^{b}$ & $230.8 \pm 10.8^{b}$ & $230.7 \pm 21.1^{b}$ & $4.82 \pm 0.33^{b}$ & $193.5 \pm 9.24^{b}$ \\
\hline CD 20+CP & $130.8 \pm 6.96^{c}$ & $165.5 \pm 9.08^{c}$ & $145.2 \pm 4.91^{c}$ & $2.56 \pm 0.27^{c}$ & $122.0 \pm 7.43^{c}$ \\
\hline
\end{tabular}

$\mathrm{CD}=$ Cimetidine, $\mathrm{CP}=$ Cyclophosphamide, Values are expressed as Mean $\pm S E M, n=6$ aSignificant $(P<0.05)$ difference when compared to control

bSignificant $(P<0.05)$ difference when compared to $C P$

'Significant $(P<0.01)$ difference when compared to $C P$ 
+ CP showed fatty change and disorganisation of liver architecture (Fig $1 \mathrm{f}-\mathrm{h}$ ).

\section{DISCUSSION}

Chemotherapy has been used for many years and is still one of the most common treatments for cancer. Cyclophosphamide (CP) is a cytotoxic alkylating agent that is widely used as a chemotherapeutic agent in the treatment of cancer and autoimmune disorders. However, hepatotoxicity is one of the drawbacks that could limit the use of $\mathrm{CP}$ and deprived patients of therapeutic benefits. ${ }^{26}$
Studies using animal model of xenobiotic-induced hepatotoxicity have reported the potential of cimetidine as a hepatoprotective agent ${ }^{27}$. This study was designed to examine the possible benefit that could be derived from cimetidine as a remedy for cyclophosphamideinduced liver toxicity in albino rats. The use of CP can cause alterations in body and organ weight as a sign of toxicity. ${ }^{28}$ In this study, body weight, relative and absolute liver weights were not altered in CP-administered rats. The aminotransferases (ALT and AST) are the most frequently utilized and specific indicators of hepatocellular necrosis. These enzymes catalyze the transfer of alpha amino acids of aspartate and alanine respectively to the alpha

\begin{tabular}{|c|c|c|c|c|c|}
\hline $\begin{array}{l}\text { Dose } \\
(\mathrm{mg} / \mathrm{kg})\end{array}$ & $\begin{array}{c}\text { SOD } \\
\text { (U/mg protein) }\end{array}$ & $\begin{array}{c}\text { CAT } \\
\text { (U/mg protein) }\end{array}$ & $\begin{array}{c}\text { GSH } \\
(\mu \mathrm{g} / \mathrm{mg} \text { protein) }\end{array}$ & $\begin{array}{c}\text { GPX } \\
\text { (U/mg protein) }\end{array}$ & $\begin{array}{c}\text { MDA } \\
\text { (nmol/mg protein) }\end{array}$ \\
\hline Control & $34.8 \pm 2.89$ & $54.9 \pm 3.20$ & $18.5 \pm 2.70$ & $18.2 \pm 3.19$ & $0.17 \pm 0.04$ \\
\hline CD 5 & $35.8 \pm 2.99$ & $55.8 \pm 3.84$ & $20.5 \pm 1.15$ & $18.6 \pm 1.38$ & $0.14 \pm 0.02$ \\
\hline CD 10 & $36.5 \pm 3.33$ & $56.6 \pm 3.14$ & $19.9 \pm 2.36$ & $17.7 \pm 2.22$ & $0.13 \pm 0.01$ \\
\hline CD 20 & $37.7 \pm 2.03$ & $57.3 \pm 5.44$ & $19.6 \pm 1.42$ & $17.7 \pm 1.71$ & $0.12 \pm 0.02$ \\
\hline CP 150 & $14.7 \pm 1.24^{a}$ & $18.1 \pm 1.92^{\mathrm{a}}$ & $4.05 \pm 0.65^{a}$ & $4.79 \pm 0.78^{a}$ & $1.53 \pm 0.13^{a}$ \\
\hline CD 5+CP & $15.1 \pm 1.84^{b}$ & $26.3 \pm 1.80^{\mathrm{b}}$ & $7.34 \pm 0.33^{b}$ & $6.98 \pm 0.39^{b}$ & $0.90 \pm 0.46^{b}$ \\
\hline CD 10+CP & $23.3 \pm 1.57^{b}$ & $33.7 \pm 2.33^{b}$ & $11.3 \pm 1.32^{b}$ & $9.09 \pm 0.53^{b}$ & $0.52 \pm 0.05^{b}$ \\
\hline$C D 20+C P$ & $31.2 \pm 2.26^{c}$ & $49.9 \pm 1.12^{c}$ & $16.6 \pm 1.12^{c}$ & $13.3 \pm 1.68^{c}$ & $0.22 \pm 0.08^{c}$ \\
\hline
\end{tabular}

$\mathrm{CD}=$ Cimetidine, $\mathrm{CP}=$ Cyclophosphamide, values are expressed as Mean $\pm S E M, n=6$

aSignificant $(P<0.05)$ difference when compared to control

bSignificant $(P<0.05)$ difference when compared to $C P$

'Significant $(P<0.01)$ difference when compared to $C P$
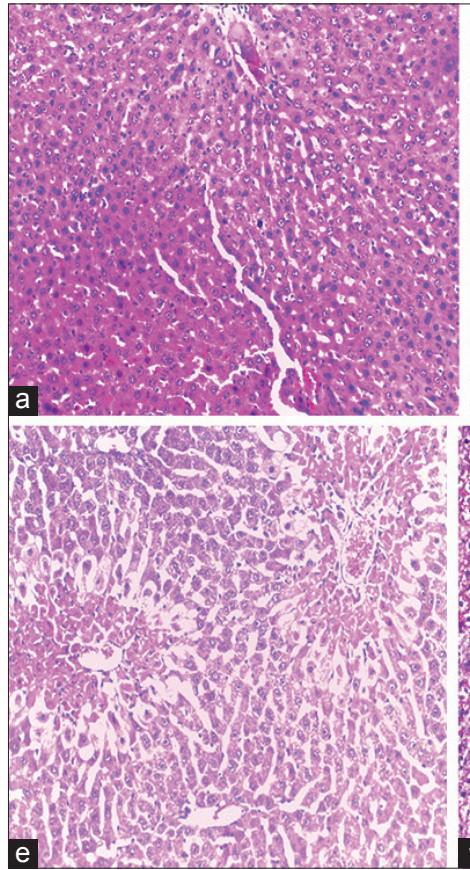
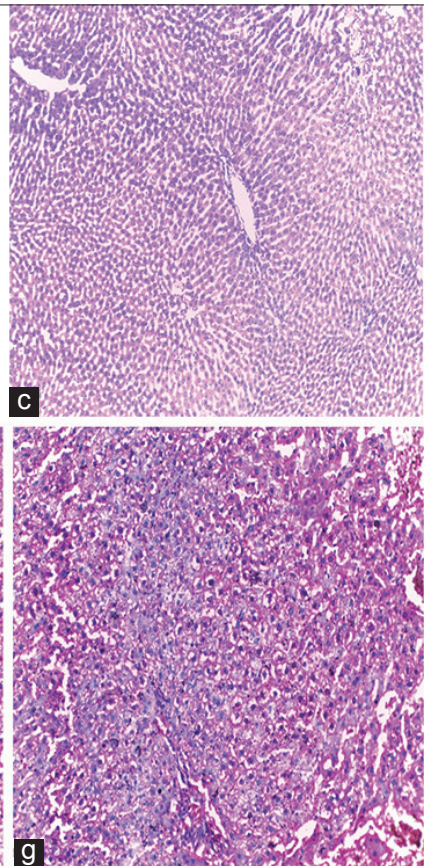

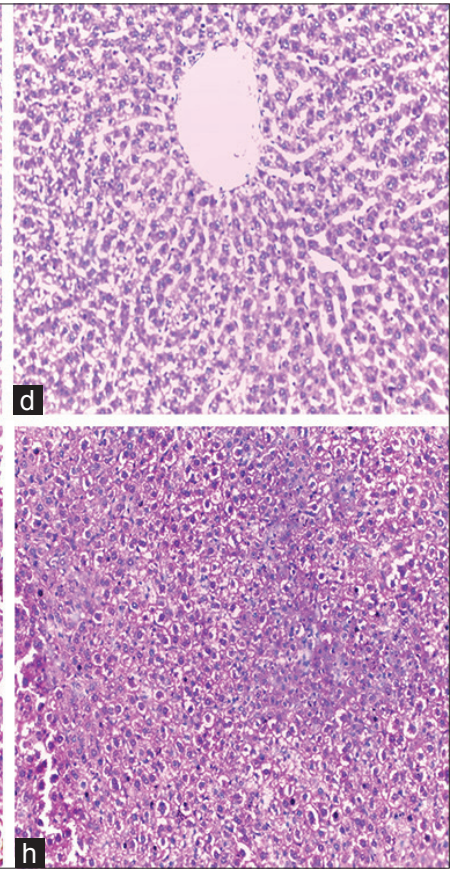

Figure 1: (a-d) Liver of control rat administered with water and the liver of rats administered with $5,10 \mathrm{and} 20 \mathrm{mg} / \mathrm{kg}$ of cimetidine showing normal histology. (e) Liver of rat administered with $150 \mathrm{mg} / \mathrm{kg}$ of cyclophosphamide showing necrosis of hepatocytes around the central veins. (f) Liver of rat administered with $5 \mathrm{mg} / \mathrm{kg}$ of cimetidine and $150 \mathrm{mg} / \mathrm{kg}$ of CP showing fatty change and disorganisation of liver architecture. (g) Liver of rat administered with $10 \mathrm{mg} / \mathrm{kg}$ of cimetidine $+150 \mathrm{mg} / \mathrm{kg}$ of CP showing fatty change and disorganisation of liver architecture. (h) Liver of rats administered with $20 \mathrm{mg} / \mathrm{kg}$ of cimetidine and $150 \mathrm{mg} / \mathrm{kg}$ of CP showing fatty change and disorganisation of liver architecture (Hand E X200) 
keto group of ketoglutaric acid. ${ }^{29}$ Alkaline phosphatase (ALP) is a marker enzyme for plasma and endoplasmic reticulum that is often employed to assess the integrity of plasma membrane. ${ }^{30} \mathrm{GGT}$ and $\mathrm{LDH}$ are enzymes present in hepatocytes which are clinically used as yardstick for liver function. ${ }^{31}$ Abnormal elevations in ALT, ALP, AST, GGT, and LDH levels are normally correlated with hepatic damage. One of the consequences of hepatic injury induced by $\mathrm{CP}$ is the leaching out of enzymes form hepatocytes resulting in increased systemic circulation and activities. ${ }^{32}$ The current study observed marked elevations in liver and serum levels of ALT, AST, ALP, GGT, and $\mathrm{LDH}$ in $\mathrm{CP}$-administered rats. This observation is a reflection of liver cellular damage and the alteration of membrane function. ${ }^{33}$ However, it is noteworthy that the levels of these enzymes were restored in rats administered with cimetidine and CP.

Bilirubin is an endogenous anion derived from the degradation of hemoglobin found in red blood cells. It is transported to the liver bound to albumin. High plasma conjugated bilirubin concentration indicates impaired hepatic excretory function. Higher serum levels of bilirubin seen in hepatitis is directly proportional to the degree of histological injury of hepatocytes and the longer course of the disease. ${ }^{34}$ This study observed that rats exposed to $\mathrm{CP}$ had higher levels of conjugated and total bilirubin. The higher levels of conjugated and total bilirubin observed in CP-intoxicated rats is a sign of toxicity and agrees with reported findings. ${ }^{35}$ This observation could be attributed to $\mathrm{CP}$-induced overproduction, impaired uptake, conjugation or excretion of unconjugated or conjugated bilirubin from hepatocytes to bile ducts. Comparatively, levels of conjugated and total bilirubin were restored in rats' administered with cimetidine + CP.

Histopathological alteration of the liver is a common and key factor in CP-induced hepatotoxicity. ${ }^{36}$ In the current study, microscopic examination of the liver of CP-treated rat shows hepatocyte necrosis around the central veins. However, the liver of CP and cimetidine administered rats showed fatty change and disorganisation of architecture. $\mathrm{SOD}$ is involved in the dismutation of superoxide anion to $\mathrm{H}_{2} \mathrm{O}_{2}$ and $\mathrm{O}_{2}$, this harmful $\mathrm{H}_{2} \mathrm{O}_{2}$ is further broken down to water by CAT while GSH and GPX are considered as the major antioxidants against free radicals and are vital constituents of detoxification pathways. ${ }^{37}$ One of the primary effects of oxidative stress is the depletion of the antioxidant defence status of an organism. Therefore measurements of antioxidant levels serve as indexes for oxidative stress. In the current study, significant decreases in liver SOD, CAT, GSH and GPX levels were observed after $\mathrm{CP}$ administration. This observation can be correlated with similar findings. ${ }^{38}$ In contrast, the levels of these antioxidants were restored in rats administered with cimetidine $+\mathrm{CP}$.

Malondialdehyde (MDA) is one of the end products of lipid peroxidation (LPO) and its level within a tissue indicates the nature and the extent of LPO. LPO is a major marker of oxidative stress, altered membrane structure, and enzyme inactivation. ${ }^{39}$ The present study observed elevated liver level of MDA in CP-administered rats. This finding is consistent with reports by some authors that lipid peroxidation is an integral aspect of $\mathrm{CP}$-induced hepatotoxicity. ${ }^{40}$ However, the liver levels of MDA were lower in rats administered with cimetidine $+\mathrm{CP}$. The precise mechanism by which $\mathrm{CP}$ causes hepatic injury is poorly known; however, numerous studies have shown that CP exposure enhances the production of intracellular reactive oxygen species (ROS), suggesting that biochemical and physiological disturbances may result from oxidative stress. ${ }^{41} \mathrm{CP}$ requires metabolic activation by hepatic microsomal cytochrome P450 mixed function oxidase system for both its therapeutic action and adverse effects. ${ }^{42}$ The metabolic conversion of CP leads to the formation of two cytotoxic metabolites; phosphoramide mustard and acrolein. Acrolein is believed to be responsible for $\mathrm{CP}$-induced liver injury. ${ }^{43} \mathrm{CP}$ metabolites can stimulate oxidative stress and depress the antioxidant defence mechanisms in the liver. ${ }^{44}$ The observed effect of cimetidine in this study could be attributed to its antioxidant activity through the scavenging of oxidative radicals generated by CP. Another possible mechanism is the inhibitory effect of cimetidine on hepatic microsomal cytochrome P450 mixed function oxidase system thereby preventing the biotransformation of $\mathrm{CP}$ to its toxic metabolites.

\section{ACKNOWLEDGMENT}

The authors appreciated the technical assistance of Obiajuru Miriam of the Faculty of Pharmacy Madonna University, Elele, Rivers State.

\section{REFERENCES}

1. Anand $P$, Kunnumakkara $A B$, Kunnumakara $A B$, Sundaram $C$, Harikumar KB, Tharakan ST, et al. Cancer is a preventable disease that requires major lifestyle changes. Pharm Res 2008; 25 (9): 2097-2116.

2. Zhao $\mathrm{G}$ and Rodriguez BL. Molecular targeting of liposomal nanoparticlesto tumor microenvironment. Int Jour of Nanomed 2013; 8; 61-71.

3. Jabir NR, Tabrez S, Ashraf GM, Shakil S, Damanhouri GA and Kamal MA. Nanotechnology-based approaches in anticancer research. Int Jour of Nanomed 2012;7: 4391-4408.

4. Xu G and McLeod HL. Strategies for enzyme/prodrug cancer therapy. Clin Cancer Res 2001; 7: 3314-3324. 
5. Emadi A, Jones RJ and Brodsky RA. Cyclophosphamide and cancer: golden anniversary. Nat Rev Clin Oncol 2009; 6: 638-647.

6. Hales BF. Comparison of the mutagenicity and teratogenicity of cyclophosphamide and its active metabolites, 4-hydroxycyclophosphamide, phosphoramide mustard, and acrolein. Cancer Res 1982; 42(8):3016-3021.

7. Kern JC and Kehrer JP. Acrolein-induced cell death: a caspaseinfluenced decision between apoptosis and oncosis/necrosis. Chem Biol Interact 2002;139(1):79-95.

8. Muratori L, Ferrari R, Muratori P, Granito A and Bianchi FB. Acute icteric hepatitis induced by a short course of low-dose cyclophosphamide in a patient with lupus nephritis. Dig Dis Sci 2005; 50(12):2364-2365.

9. Stankiewicz A, Skrzydlewska E and Makieła M. Effects of amifostine on liver oxidative stress caused by cyclophosphamide administration to rats. Drug Metab and Drug Inter 2002; 19 (2): 67-82.

10. Arumugam $\mathrm{N}$, Sivakumar $\mathrm{V}$, Thanislass $\mathrm{J}$ and Devaraj $\mathrm{H}$. Effects of acrolein on rat liver antioxidant defense system. Indian J Exp Biol 1997; 35(12):1373-1374.

11. Reiter R, Tang L, Garcia JJ and Munoz-Hoyos A. Pharmacological actions of melatonin in oxygen radical pathophysiology. Life Sci 1997;60(25): 2255-2271.

12. Jahangirvand $M$, Minai-Tehrani $D$, Yazdi $F$, Minai-Tehrani $A$ and Razmi N. Binding of cimetidine to Balb/C mouse liver catalase; kinetics and conformational studies. Curr Clin Pharmacol 2016; 11(1):7-21.

13. Altman DF. Drugs used in gastrointestinal diseases. In: B. G. Katzung. (Ed.), Basic and Clinical Pharmacology, $7^{\text {th }}$ edition, Appleton and Lange Medical Publisher, Connecticut, USA. 1998; 1019-1020.

14. Speeg KV, Patwardhan RV, Avant GR, Mitchell MC and Schenker S. Inhibition of microsomal drug metabolism by histamine $\mathrm{H} 2$-receptor antagonists studied in vivo and in vitro in rodents. Gastro 1982; 82:89-96.

15. Knodell RG, Holtzman JL, Crankshaw DL, Steele NM and Stanley LN. Drug metabolism by rat and human hepatic microsomes in response to interaction with $\mathrm{H} 2$-receptor antagonists. Gastro 1982; 82:84-88.

16. Mitchell MC, Schenker S, Avant GR and Speeg KV. Cimetidine protects against acetaminophen hepatotoxicity in rats. Gastro 1981; 81(6):1052-1060.

17. Speeg KV, Mitchell MC and Maldonado AL. Additive protection of cimetidine and $\mathrm{N}$-acetylcysteine treatment against acetaminophen-induced hepatic necrosis in the rat. J Pharmacol Exp Ther 1985; 234(3):550-554.

18. Lambat Z, Limson JL and Daya S. Cimetidine: antioxidant and metal-binding properties. J Pharm Pharmacol 2002; 54(12):1681-1686.

19. Ching TL, Haenen $G$ and Bast $A$. Cimetidine and other $H 2$ receptor antagonists as powerful hydroxyl radical scavengers Chemico-Biol Inter 1993; 86(2):119-127.

20. Gornall AG, Bardawill CJ and David MM. Determination of serum proteins by means of the biureto reaction. J Biol Chem 1949; 177: 751-766.

21. Buege JA and Aust SD. Microsomal lipid peroxidation. Methods Enzymol 1978; 52: 302-310.

22. Aebi $\mathrm{H}$ Catalase in vitro. In Method in Enzymology 1984; 105: 121-126.

23. Sun M and Zigma S. An Improved Spectrophotometer Assay of Superoxide Dismutase Based On Epinephrine Antioxidation Anal Biochem 1978; 90: 81-89.
24. Sedlak $\mathrm{J}$ and Lindsay RH. Estimation of Total, Protein-Bound, and Nonprotein Sulfhydryl Groups in Tissue with Ellman's Reagent. Anal Biochem 1968; 25: 1192-1205.

25. Rotruck JT, Rope AL, Ganther HF and Swason AB. Selenium: biochemical role as a component of glutathione peroxidase. Science 1973; 179: 588-590.

26. Selvakumar E, Prahalathan $\mathrm{C}$ and Varalakshmi P. Modification of cyclophosphamide-induced clastogenesis and apoptosis in rats by a-lipoic acid. Mutat Res-Genet Toxicol Environ 2006; 606: 85-91.

27. Sajedianfard $\mathrm{J}$, Khodakaram-Tafti $\mathrm{A}$ and Esmailpour $\mathrm{H}$. Therapeutic effect of cimetidine on acetaminophen-induced hepatotoxicity in rats. Comp Clin Pathol 2006;15:55-57.

28. Kanno TN, Sensiate LA, de Paula NA and Sparça Salles MJ. Toxic effects of different doses of cyclophosphamide on the reproductive parameters of male mice. Bra Jour Pharm Sci 2009; 45(2): 314-319.

29. Rosen HR and Keefe EB. Evaluation of abnormal liver enzymes, use of liver tests and the serology of viral hepatitis: Liver disease, diagnosis and management. $1^{\text {st }}$ ed. New York; Churchill livingstone. 2000; 24-35.

30. Kwo PY, Cohen SM and Lim JK. Practice Guideline: Evaluation of Abnormal Liver Chemistries Am J Gastroenterol advance online publication 2016;517.

31. Abdel-Reheim AM, Messiha BS and Abo-SaifA. Hepatoprotective Effect of Diosmin on Iron-induced Liver Damage. Intern Jour of Pharm 2017; 13: 529-540.

32. Senthikumar S, Ebenezer KK, Sathish $\mathrm{Y}$, Yogeeta $\mathrm{S}$ and Devaki T. Modulation of the tissue defense system by squalene in cyclophosphamide induced toxicity in rats. Arch Med Sci 2006; 2: 94-100.

33. Kumar G, Banu GS, Kannan V and Pandian MR. Antihepatotoxic effect of beta-carotene on paracetamol induced hepatic damage in rats. Indian J Exp Biol 2005;43:351-355.

34. Thapa BR and Walia A. Liver Function Tests and their Interpretation Indian J Pediatr 2007; 74 (7): 663-671.

35. Ukpo GE, Ehianeta TS and Salako OA and Adegoke AY. Evaluation of the haematological and biochemical effects of averon $\circledast$, a herbal formulation, against cyclophosphamideinduced immunomodulated male rats. IJPSR 2013; 4(9): 3556-3562.

36. Selvakumar E, Prahalathan C, Mythili $Y$ and Varalakshmi P. Mitigation of oxidative stress in cyclophosphamide-challenged hepatic tissue by DL- $\alpha$-lipoic acid, Molecular and Cellular Biochemistry 2005; 272 (1-2):179-185.

37. Matés JM, Pérez-Gómez $C$ and Núñez de Castro I. Antioxidant enzymes and human diseases. Clin Biochem 1999;32:595-603.

38. Mbong AM, Djiokeng PG, Ntentie FR, Dimodi H, Ngondi JL and Oben EJ. Protective effect of hydroethanolic extracts of Solanum scabrum and Cola verticillata against cyclophosphamide induced toxicity in female rats. J Food Res 2014;3:18-30.

39. Barrera G. Oxidative stress and lipid peroxidation products in cancer progression and therapy. ISRN Oncol 2012; 137289.

40. Adams JD and Klaidman LK. Acrolein-induced oxygen radical formation. Free Radic Biol Med 1993;15:187-193.

41. Ghosh D, Das UB, Ghosh S, Mallick M and Debnath J. Testicular gametogenic and steroidogenicactivities in cyclophosphamide treated rat: a correlative study with testicular oxidative stress. Drug Chem Toxicol 2003; 25: 281-292.

42. Dollery C. Therapeutic Drugs, Churchill Livingstone, Edinburgh, UK, 1999. S126-S129. 
43. Honjo, SuouTand Hirayama C. Hepatotoxicity of cyclophosphamide in man: pharmacokinetic analysis Res Comm in Chem Path and Pharm 1988; 61(2):149-165.

44. Bhattacharya A, Lawrence RA, Krishnan A, Zaman K, Sun D and
Fernandes $\mathrm{G}$. Effect of dietary $\mathrm{n}-3$ and $n-6$ oils with and without food restriction on activity of antioxidant enzymes and lipid peroxidation in livers of cyclophosphamide treated autoimmune-prone NZB/W female mice. Jour Amer Coll of Nutr 2003; 22(5):388-399.

\section{Authors Contribution:}

EA- Concept and design of the study, literature search, statistical analysis, interpretation of manuscript preparation and critical revision of manuscript; BB- Concept, collected data and review of literature, preparation of first draft of manuscript and critical revision of manuscript.

Study Attributed to: Department of Pharmacology and Toxicology, Faculty of Pharmacy, Niger Delta University, Nigeria.

\section{Orcid ID:}

Dr. Adikwu Elias - (D) https://orcid.org/0000-0003-4349-8227

Dr. Bonsome Bokolo - (D) https://orcid.org/0000-0001-6426-6228

Source of Support: Nil, Conflict of Interest: None declared. 